\title{
Impact of Haemophilus influenzae type b
}

Haruko Takeuchi ${ }^{1 *+}$ (D, S. M. Tafsir Hasan ${ }^{2 \dagger}$, Khalequ Zaman³, Sayaka Takanashi, ${ }^{4,5}$, Samar Kumar Hore ${ }^{6}$, Sultana Yeasmin ${ }^{2}$, Shaikh Meshbahuddin Ahmad ${ }^{3,7}$, Md Jahangir Alam, ${ }^{3,8}$, Masamine Jimba' ${ }^{1}$, Tsutomu Iwata ${ }^{9}$ and Md Alfazal Khan ${ }^{2}$

\begin{abstract}
Background: Although the prevalence of bronchial asthma has been increasing worldwide since the 1970's, the prevalence among 5-year-old children was significantly lower in 2016 than in 2001 in rural Bangladesh. We aimed to determine whether the Haemophilus influenzae type b (Hib) combination vaccination (without booster) started in 2009 contributed to this decrease.

Methods: A case-control study was conducted among 1658 randomly selected 5-year-old children from Matlab, Bangladesh. Data on wheezing were collected using the International Study of Asthma and Allergies in Childhood questionnaire. The vaccination data were collected from the records of the Matlab Health and Demographic Surveillance System, while data on pneumonia were obtained from the clinical records of Matlab Hospital. Adjusted odds ratios (aORs) were calculated for the risk for wheezing. The reduction rate was calculated to determine the impact of the vaccination on pneumonia history between the present study and our previous study conducted in 2001 by using the following formula: (percentage of pneumonia cases in 2001 - percentage of pneumonia cases in 2016)/ (percentage of pneumonia cases in 2001) times 100 (\%).
\end{abstract}

Results: Hib combination vaccination was a protecting factor against wheezing (aOR: $0.50 ; p=0.010$ ), while pneumonia at 1, 2, 3-4 years of age were risk factors for wheezing (aOR: 2.86, 3.19, 2.86; $p=0.046,0.030,0.030$, respectively). The history of pneumonia was significantly lower in the 2016 study participants than those in 2001 both in the overall cohort and the wheezing group (paired t-test: $p=0.012, p<0.001$, respectively). Whereas the history of pneumonia decreased when the children grew older in the 2001 overall cohort, it peaked at the age of 2 years in 2016 wheezing

\footnotetext{
*Correspondence: htakeuchi-tky@umin.net

${ }^{\dagger}$ Haruko Takeuchi and S. M. Tafsir Hasan contributed equally to this work

${ }^{1}$ Department of Community and Global Health, Graduate School

of Medicine, The University of Tokyo, 7-3-1 Hongo, Bunkyo City, Tokyo

113-0033, Japan

Full list of author information is available at the end of the article
}

(c) The Author(s) 2021. Open Access This article is licensed under a Creative Commons Attribution 4.0 International License, which permits use, sharing, adaptation, distribution and reproduction in any medium or format, as long as you give appropriate credit to the original author(s) and the source, provide a link to the Creative Commons licence, and indicate if changes were made. The images or other third party material in this article are included in the article's Creative Commons licence, unless indicated otherwise in a credit line to the material. If material is not included in the article's Creative Commons licence and your intended use is not permitted by statutory regulation or exceeds the permitted use, you will need to obtain permission directly from the copyright holder. To view a copy of this licence, visit http://creativecommons.org/licenses/by/4.0/. The Creative Commons Public Domain Dedication waiver (http://creativeco mmons.org/publicdomain/zero/1.0/) applies to the data made available in this article, unless otherwise stated in a credit line to the data. 
group. The reduction rate decreased when children grew older in both the overall cohort and the wheezing group, however, it decreased faster in the wheezing group.

Conclusions: Hib combination vaccination was a protective factor against wheezing in 0-year-old children. However, the effects of vaccination might have attenuated at the ages of 1-4 years, because no booster dose was administered. The addition of a booster dose might further decrease the prevalence of asthma and wheezing.

Keywords: Asthma, Bangladesh, Child, Haemophilus influenzae type b vaccine, Administration and dosage, Pneumonia, Protective factor

\section{Background}

Bronchial asthma is characterized by chronic inflammation and hyper-responsiveness of the airway and is one of the most common chronic diseases of childhood [1]. The established risk factors for asthma are atopy and respiratory tract infections $[2,3]$. The contribution of environmental factors to the development of asthma first came to light when the prevalence of asthma markedly increased in the 1970's in industrialized and high-income countries [4-6], as it appeared unlikely that genetic factors alone would have contributed to this sudden increase. Indeed, subsequent epidemiological studies did find a large variation in the worldwide prevalence of asthma, and confirmed that asthma was more common among children in urban, industrial and affluent areas than among children in rural areas $[7,8]$. More recently, however, a significant decline in the prevalence of wheezing was found among 5 -year-old children in rural Bangladesh, from $16.2 \%$ in 2001 to $8.7 \%$ in $2016[9,10]$, despite the obvious improvement in socio-economic status (SES) during this period. A nationwide cross-sectional survey in 1999 reported a prevalence rate of $7.3 \%$ for asthma among children aged 5-14 years [11], while a study in 2000 documented a prevalence rate of $9.1 \%$ for "current wheezing" among school children aged 6-7 years [12]. In 2001, the asthma prevalence among 5-year-old children was documented as $16 \%$ [9], and in 2003, an even higher prevalence of current wheezing, nearly $20 \%$, was recorded among 5 -yearold children in rural Bangladesh [13]. These findings imply that some specific factor must have inhibited the high prevalence of wheezing or asthma, although the studies were not based on the same methods.

Meanwhile, there had been a lot of improvements in the area which influenced child health including the care of respiratory infections, which is a strong risk factor for wheezing and asthma. The mortality from respiratory tract infections greatly decreased due to various and rigorous measures. These include antibiotic use by the community health research workers (CHRWs), Vitamin A distribution, improved hospital care, improved referral, improved nutritional status, etc. Pneumoccocal vaccine was also introduced in 2015, which the participants of the 2016 study were not administered, though.
In 2009, the Expanded Program on Immunization (EPI) of Bangladesh introduced three doses of Haemophilus influenzae type $\mathrm{b}$ (Hib) combination vaccine,

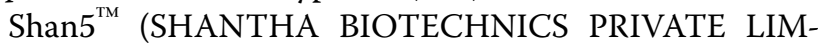
ITED, Telangana, India), in the form of pentavalent vaccine that included Diphtheria, Tetanus and Pertussis (DTP) vaccine, hepatitis $\mathrm{B}$ vaccine and $\mathrm{Hib}$ vaccine without a booster dose. Besides, in 2004, Bangladesh started the national deworming program, which was developed to administer anti-helminthic drugs to children aged 24-59 months, with another program (also initiated in 2004) that delivered the same drugs to primary school children to eliminate soil-transmitted helminthiasis.

In rural Bangladesh in 2001, 26\% of childhood wheezing was attributable to anti-Ascaris IgE [14], and 16\% of childhood wheezing was attributable to the history of pneumonia during young childhood [14], which was the major causes of death of young children in Bangladesh [15]. The prevalence of wheezing seems to have decreased concurrently with the decrease in the prevalence of Ascaris infection, implying that the implementation of the deworming program caused the decrease [10]. However, Ascaris infection itself was not found to be a risk factor for wheezing [10].

While the Hib combination vaccine has been reported to prevent invasive infectious diseases by $\mathrm{Hib}$, such as meningitis [16], it also had an impact on pneumonia, which proved to be a strong risk factor for asthma and wheezing $[9,14]$, and has even been reported to lead to herd protection in Bangladesh [17]. Since few studies have reported the association of Hib vaccination with childhood asthma and wheezing, the present study aimed to determine if the introduction of Hib combination vaccination and various measures for pneumonia in Bangladesh contributed to the reduction in childhood asthma and wheezing, through pneumonia prevention.

\section{Methods}

The aim, design and setting of the study

The aim of the present study is to determine if Hib vaccination contributed to the decrease of asthma and wheezing through pneumonia prevention. 
We conducted this case-control study on the risk of Hib combination vaccination and history of pneumonia for asthma symptoms among 5-year-old children in Matlab. We also compared the results of the present study with those of our previous study (described below) to determine whether Hib combination vaccination contributed to decrease pneumonia prevalence [9], the result of which was partially unpublished. We finally compared death from respiratory infections including pneumonia among children under 5 years of age in the area before and after the introduction of Hib combination vaccination using reports of health and demographic surveillance system (HDSS) run by icddr,b, formerly the International Centre for Diarrhoeal Disease Research, Bangladesh (ICDDR,B), to determine the impact of Hib combination vaccination on pneumonia related mortality [18-24].

Matlab is a low-lying riverine area, where the principal occupations are farming and fishing. Since 1966, the HDSS, which consists of regular cross-sectional censuses and the longitudinal registration of vital events, has been maintained in the area by the icddr,b [24]. The population of the HDSS area, which encompasses 142 villages, was approximately 220,000 in 2001 and 230,000 in 2014 when the present study was initially planned. A maternal and child health, and family-planning program serve approximately half of the population of the HDSS area (the icddr,b service area, which covers 67 villages). A recordkeeping system (RKS) records all instances of immunization in the service area.

The present study was conducted from December 2015 to October 2016, and planned to include 1800 children aged 5 years who were randomly selected from all 67 villages of the HDSS service area. A total of 1658 children ultimately participated in the study. The International Study of Asthma and Allergies in Childhood questionnaire was used to identify wheezing. One hundred and forty-five children had experienced wheezing during the previous 12 months and 1513 children had not. The 145 children who experienced wheezing during the previous 12 months were placed in the "wheezing" group and 1513 children who did not experience wheezing during the previous 12 months were placed in the "non-wheezing" group. The participants of this study were able to receive Hib combination vaccine since it was introduced in the area in 2009. We compared these children with the participants of our former study conducted in 2001. The total population of our 2001 study consisted of 1705 children, who were all children aged 5 years from 51 villages that were themselves randomly selected from the service area [9]. Data on deaths from respiratory infections including pneumonia were obtained from the Matlab HDSS Scientific Reports published by the icddr,b [18-24].
The study protocol was approved by the Ethical Review Committee of the icddr,b (PR-15054). The Ethics Committee of Tokyo Kasei University (Sayama H27-09), and The University of Tokyo (11018 and 2020180NI) approved the study. The protocol of our 2001 study was approved by the Ethical Review Committee of the International Centre for Diarrhoeal Disease Research, Bangladesh (2000-038). As the studies involved human subjects, the ethical principles of the Declaration of Helsinki were followed. Written informed consent was obtained from the legal guardians of all participants.

\section{Field data collection}

The procedures used for data collection in the present study have been described elsewhere [10]. In brief, trained local field-research assistants visited the homes of the children and collected information using a semistructured, pre-tested questionnaire adopted from the International Study of Asthma and Allergies in Childhood questionnaire [25]. Wheezing was defined as any episode of wheezing or whistling in the chest in the 12 months preceding the interview. Children who answered "No," to the above question were placed in the "non-wheezing" group. Information was also collected regarding family history of allergy, SES, and environmental factors. Information on the participants' history of pneumonia was retrieved from Matlab Hospital clinical records. Children with suspected pneumonia had been referred to Matlab Hospital from the CHRWs and the diagnosis of pneumonia was based on the WHO guidelines for the management of common illnesses with limited resources [26].

The procedures used for data collection in the 2001 study have also been previously described [9]. In 2001, Episodes of pneumonia was obtained from the RKS of Matlab HDSS. Pneumonia was recorded in the RKS by CHRWs during surveillance (performed every 2 weeks), based on statements from mothers regarding increased respiratory rates with or without chest indrawing.

\section{Numbers of death from respiratory infections including pneumonia and mid-year population} Information on deaths from respiratory infections including pneumonia among children under 5 years of age and the mid-year population in the area were obtained from HDSS Scientific Report Nos. 74, 82, 90, 103, 109, 121, and 138 published by the icddr,b [18-24]. The number of deaths from respiratory infections that include acute respiratory infection, pneumonia and influenza at $<1$ year old and at 1-4 years old in the years 1991, 1996, 2001, 2006, 2009, 2011, and 2016, in the icddr,b service area of Matlab HDSS, as recorded in the Matlab HDSS Scientific Reports, were compared to find out the decrease in 
mortality. Since the 5-year-old participants of the 2001 study were $<1$ year of age in 1996, and the 5 -year-old participants of the 2016 study were $<1$ year of age in 2011, the data for 1996 and 2011 are included here. Similarly, the data for 2006 and 2008 are included to compare the pre and post effect Hib combination vaccine on children of $<1$ year of age and 1-4 years of age, respectively.

\section{Statistical analysis}

This study was initially planned to determine the impact of the national deworming program on wheezing [9]. Therefore, the sample size was determined based on the levels of anti-Ascaris IgE. We calculated the sample size based on the assumption that at least $16 \%$ of children aged 60-71 months would have wheezing [27]. Given $80 \%$ power and a 5\% significance level, 209 children in each group were required to detect a difference of $1.8 \mathrm{U}_{\mathrm{A}} / \mathrm{mL}(\mathrm{SD}, 1.5)$ to $1.4 \mathrm{U}_{\mathrm{A}} / \mathrm{mL}(\mathrm{SD}, 1.4)$ in the values of serum anti-Ascaris IgE levels between the wheezing and never-wheezing groups of children. Thus, we needed to recruit 240 children for the children with and without wheezing each, assuming a $15 \%$ refusal rate (including absences). To obtain the required number of children for the wheezing group, we needed to approach 1800 individuals, assuming a $20 \%$ loss due to absences, refusal, and other reasons.

Data were analyzed using IBM SPSS Statistics version 26 (IBM Japan, Tokyo, Japan). First, the prevalence of wheezing was calculated. An initial exploratory analysis was conducted to determine the distribution of the independent variables. After each variable had been subjected to a descriptive analysis between the children with and without wheezing, continuous variables (e.g., height) were compared using a $t$-test (if approximately normally distributed) or Mann-Whitney $U$ test (if not normally distributed), and categorical variables were compared using a $x^{2}$ test. Then, the odds ratios for wheezing, with or without adjustments for risk factors, were calculated using multiple logistic regression analysis, with wheezing status as the outcome variable. Then, we compared the reduction in the history of pneumonia from 2001 to 2016 across for each age at the time of pneumonia history, and this reduction between 2001 and 2016 was analyzed using the paired $t$-test in both the overall study population and the wheezing group. We also compared the history of pneumonia between the 2001 and 2016 study participants for each age at the time of pneumonia development by using the $x^{2}$ test. We then defined the reduction rate of pneumonia $(\%)=$ (percentage of pneumonia cases in 2001 - percentage of pneumonia cases in 2016)/ (percentage of pneumonia cases in 2001) times 100 (\%), and made a graph to visualize it. The number of deaths from pneumonia among children aged 0 and $1-4$ years during the period from 1991 to 2016 was analyzed using the $X^{2}$ test to determine the impact of various measures, such as antibiotic use by the CHRWs, Vitamin A distribution, improved hospital care, improved referral, improved nutritional status, including Hib combination vaccination, on mortality from respiratory infections including pneumonia in this area.

\section{Results}

\section{Factors associated with wheezing}

In the present study, the prevalence of wheezing during the 12 months prior to the survey was $8.7 \%$ (95\% confidence interval [CI] 7.4\%, 10.1\%). The characteristics of the study participants are presented in Table 1 . Wheezing children received significantly less Hib combination vaccination than children without wheezing, while antibiotic use during the first 1 year of life, a history of pneumonia at 1,2, 3 and 4 years of age, parental asthma and allergic rhinitis were significantly more common in children with wheezing than in children without wheezing. Hib combination vaccination was a protective factor against wheezing (OR: $0.50 ; p=0.001$ ), while antibiotic use during the first 1 year of life, a history of pneumonia at 1 year of age (OR: $2.86, p=0.046)$, at 2 years of age (OR: 3.18; $p=0.030)$, at $3-4$ years of age (OR: $3.69 ; p=0.030)$, and parental asthma were risk factors for wheezing (Table 2). Crude and adjusted odds ratios of pneumonia history at $<1$ year were not significant for wheezing.

\section{Pneumonia and wheezing}

The history of pneumonia decreased as the children grew older in the 2001 study participants in both the overall cohort and the wheezing group. In contrast, it peaked at the age of 2 years in the 2016 wheezing group, whereas the history seems almost the same across the years in the 2016 overall cohort (Table 3 ).

The pneumonia history significantly decreased from 2001 to 2016 in both the overall cohort and the wheezing group (paired t-test: $p=0.014$ and $p<0.001$, respectively). We found that in both the overall cohort and the wheezing group the pneumonia histories at the age of $<1$ year, 1 year and 2 years significantly decreased in the 2016 (Fisher two-tailed exact test: $p<0.001$ ), however, the pneumonia history did not significantly decrease at the age of 3-4 years in either of the overall study population or the wheezing group ( $p=0.196$ and 1.000 , respectively) (Table 3).

\section{Deaths due to pneumonia}

Table 4 shows that the percentage of deaths from respiratory infections including pneumonia continued to decrease significantly from 1996 to 2016 aged < 1 year 
Table 1 Characteristics of the children by wheezing

\begin{tabular}{|c|c|c|c|c|}
\hline & & $\begin{array}{l}\text { Wheezing } \\
(n=145)\end{array}$ & $\begin{array}{l}\text { Non-wheezing } \\
(n=1513)\end{array}$ & $p$ \\
\hline Sex & $M / F$ & 73/72 (50.3\%) & $731 / 782(48.3 \%)$ & 0.640 \\
\hline Height & $\mathrm{cm}$ & $107.0 \pm 5.1$ & $107.9 \pm 5.4$ & 0.073 \\
\hline Weight & $\mathrm{kg}$ & $16.4 \pm 2.7$ & $16.5 \pm 2.8$ & 0.449 \\
\hline Hib vaccine ${ }^{a}$ & Yes & $125(86.2 \%)$ & $1397(92.3 \%)$ & 0.001 \\
\hline Deworming $^{b}$ & Yes & $144(99.3 \%)$ & $1503(99.3 \%)$ & 0.968 \\
\hline Use of antibiotics ${ }^{c}$ & Yes & $138(95.2 \%)$ & $1315(87.0 \%)$ & 0.004 \\
\hline Contact with livestock ${ }^{d}$ & Yes & $72(49.7 \%)$ & $671(44.4 \%)$ & 0.220 \\
\hline \multicolumn{5}{|l|}{ Pneumonia history (years) ${ }^{e}$} \\
\hline 0 & Yes & $4(2.8 \%)$ & $32(2.1 \%)$ & 0.549 \\
\hline 1 & Yes & $7(4.8 \%)$ & $17(1.1 \%)$ & 0.003 \\
\hline 2 & Yes & $12(8.3 \%)$ & $18(1.2 \%)$ & $<0.001$ \\
\hline $3-4$ & Yes & $10(6.9 \%)$ & $14(0.9 \%)$ & $<0.001$ \\
\hline Mother has asthma & Yes & $24(16.6 \%)$ & 105 (6.9\%) & $<0.001$ \\
\hline Mother has rhinitis & Yes & $38(26.4 \%)$ & 289 (19.1\%) & 0.040 \\
\hline Father has asthma & Yes & $19(13.1 \%)$ & $61(4.0 \%)$ & $<0.001$ \\
\hline Father has rhinitis & Yes & $36(24.8 \%)$ & $200(13.2 \%)$ & $<0.001$ \\
\hline Monthly household income ${ }^{f}$ & $\mathrm{BDT}^{f}$ median & $10,000(8000,20,000)$ & $12,000(9000,20,000)$ & 0.228 \\
\hline
\end{tabular}

a Record of Hib vaccine was drawn from the record of Matlab HDSS

b Has the child received any deworming drug?

c Did you give antibiotics during the first 12 months of your child's life?

d Did the child have regular contact (at least once a week) with farm animals or livestock (e.g., cattle, goats, sheep, and poultry) during the first year of life?

e Data on pneumonia history were obtained from the clinical charts of Matlab Hospital, and pneumonia was diagnosed based on WHO criteria [20]

f Bangladesh Taka (1 Taka $=\$ 0.012)$

Table 2 Risk factors for wheezing

\begin{tabular}{lllllll}
\hline & & $\mathbf{N}$ & Crude OR $^{\mathbf{a}} \mathbf{( 9 5 \% ~ C l )}$ & $\boldsymbol{p}$ & Adjusted OR (95\% Cl) $^{\mathbf{a}}$ & $\boldsymbol{p}$ \\
\hline Sex & M/F & $804 / 854$ & $1.08(0.77-1.53)$ & 0.640 & $1.02(0.71-1.45)$ & 0.931 \\
Use of antibiotics & Yes/no & $1453 / 205$ & $2.97(1.37-6.44)$ & 0.006 & $2.74(1.24-6.06)$ & 0.013 \\
Hib vaccine & Yes/no & $1522 / 136$ & $0.52(0.31-0.86)$ & 0.011 & $0.50(0.29-0.85)$ & 0.010 \\
Contact with livestock & Yes/no & $743 / 915$ & $1.24(0.88-1.74)$ & 0.220 & $1.28(0.90-1.83)$ & 0.174 \\
Pneumonia at 0 years & Yes/no & $36 / 1622$ & $1.31(0.46-3.77)$ & 0.613 & $0.72(0.23-2.30)$ & 0.579 \\
Pneumonia at 1 year & Yes/no & $24 / 1634$ & $4.46(1.82-10.95)$ & 0.001 & $2.86(1.02-8.01)$ & 0.046 \\
Pneumonia a 2 years & Yes/no & $30 / 1628$ & $7.49(3.53-15.89)$ & $<0.001$ & $3.19(1.12-9.08)$ & 0.030 \\
Pneumonia 3-4 years & Yes/no & $24 / 1634$ & $7.93(3.46-18.20)$ & $<0.001$ & $3.69(1.13-12.06)$ & 0.030 \\
Mother has asthma & Yes/no & $129 / 1529$ & $2.66(1.64-4.30)$ & $<0.001$ & $2.58(1.54-4.34)$ & 0.001 \\
Mother has rhinitis & Yes/no & $327 / 1331$ & $1.50(1.02-2.23)$ & 0.041 & $1.15(0.74-1.79)$ & 0.001 \\
Father has asthma & Yes/no & $80 / 1578$ & $3.59(2.08-6.20)$ & $<0.001$ & $2.66(1.46-4.84)$ & 0.022 \\
Father has rhinitis & Yes/no & $236 / 1422$ & $2.17(1.45-3.25)$ & $<0.001$ & $1.70(1.08-2.67)$ &
\end{tabular}

$O R$ odds ratio, $\mathrm{Cl}$ confidence interval

a Adjusted for each other

b Female is the reference category

(trend analysis: $p<0.001$ ) and at the age $1-4$ years $(p<0.001)$.

The percentages of deaths from respiratory infections including pneumonia aged $<1$ year decreased significantly from 1996 to 2011, when our study participants were $<1$ year of age ( + : Fisher two-tailed exact test: $p<0.001$ ), and from 2001 to 2006 (†: Fisher twotailed exact test: $p<0.001$ ), however, it did not differ 
Table 3 Number of the children with history of pneumonia in 2001 and 2016 study participants among the overall cohort and the wheezing group

\begin{tabular}{|c|c|c|c|}
\hline $\begin{array}{l}\text { Age of the pneumonia history } \\
\text { Overall cohort }\end{array}$ & \multicolumn{2}{|c|}{$\begin{array}{l}\text { Number of children with a history of pneumonia } \\
\mathrm{n}(\%)\end{array}$} & ( $\mathrm{X}^{2}$ test $)$ \\
\hline & $\begin{array}{l}2001 \\
(n=1580)\end{array}$ & $\begin{array}{l}2016 \\
(n=1658)\end{array}$ & $p$ \\
\hline 0 years & 287 (18.2\%) & $36(2.2 \%)$ & $<0.001$ \\
\hline 1 year & 185 (11.7\%) & $24(1.4 \%)$ & $<0.001$ \\
\hline 2 years & $101(6.4 \%)$ & $30(1.8 \%)$ & $<0.001$ \\
\hline $3-4$ years & 30 (0.9\%) & $24(0.7 \%)$ & 0.196 \\
\hline \multicolumn{4}{|l|}{ Wheezing group } \\
\hline & $\begin{array}{l}2001 \\
(n=219)\end{array}$ & $\begin{array}{l}2016 \\
(n=145)\end{array}$ & $p$ \\
\hline 0 years & $56(25.6 \%)$ & $4(2.8 \%)$ & $<0.001$ \\
\hline 1 year & $44(20.1 \%)$ & 7 (4.8\%) & $<0.001$ \\
\hline 2 years & $36(16.4 \%)$ & $12(8.3 \%)$ & $<0.001$ \\
\hline $3-4$ years & $15(3.4 \%)$ & $10(3.4 \%)$ & 1.000 \\
\hline
\end{tabular}

Table 4 Number of deaths from respiratory diseases including pneumonia and influenza

\begin{tabular}{|c|c|c|c|c|c|c|}
\hline \multirow[t]{2}{*}{ Year } & \multicolumn{3}{|l|}{0 years } & \multicolumn{3}{|l|}{ 1-4 years } \\
\hline & $\begin{array}{l}\text { Number of deaths } \\
\text { from respiratory diseases }\end{array}$ & $\begin{array}{l}\text { Mid-year } \\
\text { population }\end{array}$ & Trend & $\begin{array}{l}\text { Number of deaths } \\
\text { from respiratory diseases }\end{array}$ & $\begin{array}{l}\text { Mid-year } \\
\text { population }\end{array}$ & Trend \\
\hline 1991 & $32(1.18 \%)$ & 2709 & $p<0.001$ & $11(0.10 \%)^{\natural}$ & 11,310 & $p<0.001$ \\
\hline 1996 & $31(1.26 \%)^{\dagger}$ & 2457 & & $5(0.05 \%)^{\mathfrak{q}}$ & 9772 & \\
\hline 2001 & $29(1.09 \%)^{\ddagger}$ & 2660 & & $2(0.02 \%)^{\dagger \dagger}$ & 9807 & \\
\hline 2006 & $6(0.23 \%)^{\ddagger \S}$ & 2583 & & $1(0.01 \%)$ & 10,792 & \\
\hline 2008 & $4(0.15 \%)^{\|}$ & 2642 & & $2(0.02 \%)$ & 10,386 & \\
\hline 2011 & $6(0.25 \%)^{\dagger \S \|}$ & 2433 & & $1(0.01 \%)$ & 10,068 & \\
\hline 2016 & $3(0.11 \%)$ & 2856 & & $2(0.02 \%)^{+\dagger}$ & 10,624 & \\
\hline
\end{tabular}

${ }^{\dagger}$ When compared between these years, when our study participants were at the age of $<1$ year, the difference in the death rate at the age of $<1$ year was significant (Fisher two-tailed exact test: $p<0.001$ )

₹ When compared between these years, the differences in the death rate at the age of $<1$ year was significant (Fisher two-tailed exact: $p<0.001$ )

$\S$ When compared between these years, before the implementation of Hib combination vaccination, the difference in the death rate at the age of $<1$ year was not significant (Fisher two-tailed exact: $p=0.572$ )

$\|$ When compared between these years, before and after the implementation of Hib combination vaccination, the difference in the death rate at the age of $<1$ year was not significant (Fisher two-tailed exact: $p=0.535$ )

" When compared between these years, the differences in the death rate at 1-4 years was significant (Fisher two-tailed exact test: $p<0.001$ )

${ }^{+\dagger}$ When compared between these years, at the time of the 2001 and 2016 studies, the difference in the death rate in 1-4 years was not significant (Fisher two-tailed exact test: $p=0.292$ )

significantly when compared between 2006 and 2011 (\$: Fisher two-tailed exact test: $p=0.572$ ). Similarly, the decrease in the children aged $<1$ year was not significant before and after the implementation of the vaccination ( $\|$ : Fisher two-tailed exact test: $p=0.535$ ). The deaths from respiratory infections including pneumonia at $<1$ year old seems to have declined significantly in the year of 2006 in the area (data not shown).
In contrast, the difference at 1-4 years was significant between 1991 and 1996 (g: Fisher two-tailed exact test: $p<0.001$ ) but not significant between 2001 and 2016 ( + : Fisher two-tailed exact test: $p=0.292$ ), when our study participants of the 2001 and 2016 studies were $1-4$ years of age. The decline in the mortality among older children occurred in the early 1990's earlier than the children aged $<1$ year old. 


\section{Reduction rates of pneumonia development}

The reduction rate of pneumonia defined by the following formula $(\%)=$ (percentage of pneumonia cases in 2001 - percentage of pneumonia cases in 2016)/(percentage of pneumonia cases in 2001) times $100(\%)$ at the ages of $0,1,2$, and $3-4$ years were $87.9 \%, 88.0 \%, 71.9 \%$, and $22.2 \%$, respectively, in the overall cohort, and $89.1 \%$, $76.1 \%, 49.4 \%$, and $0 \%$, respectively, in the wheezing group (Fig. 1). Namely, whereas the reduction rate aged $<1$ year was nearly $90 \%$, the reduction rates aged $2-4$ years were nearly less than $70 \%$. It declined when the participants grew older and this decline was faster in the wheezing group.

\section{Discussion}

The prevalence of wheezing was $8.7 \%$ in the 2016 study, which was significantly lower than that in the 2001 study. The Hib vaccine was found to be a protective factor against wheezing among 5-year-old children in rural Bangladesh. In contrast, a history of pneumonia at 1 to 4 years of age, antibiotic use in the first year of life, and parental asthma were risk factors for wheezing (Table 2). The history of pneumonia decreased as the children grew older in the 2001 study in both the overall cohort and the wheezing group (Table 3 ). In contrast, it peaked at the age of 2 years in the 2016 wheezing group, whereas it was almost the same in the 2016 overall cohort. The percentage of deaths from respiratory infections including pneumonia continued to decrease significantly from 1996 to 2016 aged < 1 year and at the age $1-4$ years. The decrease was significant between 2001 and 2006 in the children aged $<1$ year and between 1991 and 1996 in the children aged 1-4 years, however it was not significant in the children aged $<1$ year between 2008 and 2011 just before and after the start of Hib combination vaccination, or between 2001 and 2016 in the children aged 1-4 years (Table 4). The pneumonia history significantly

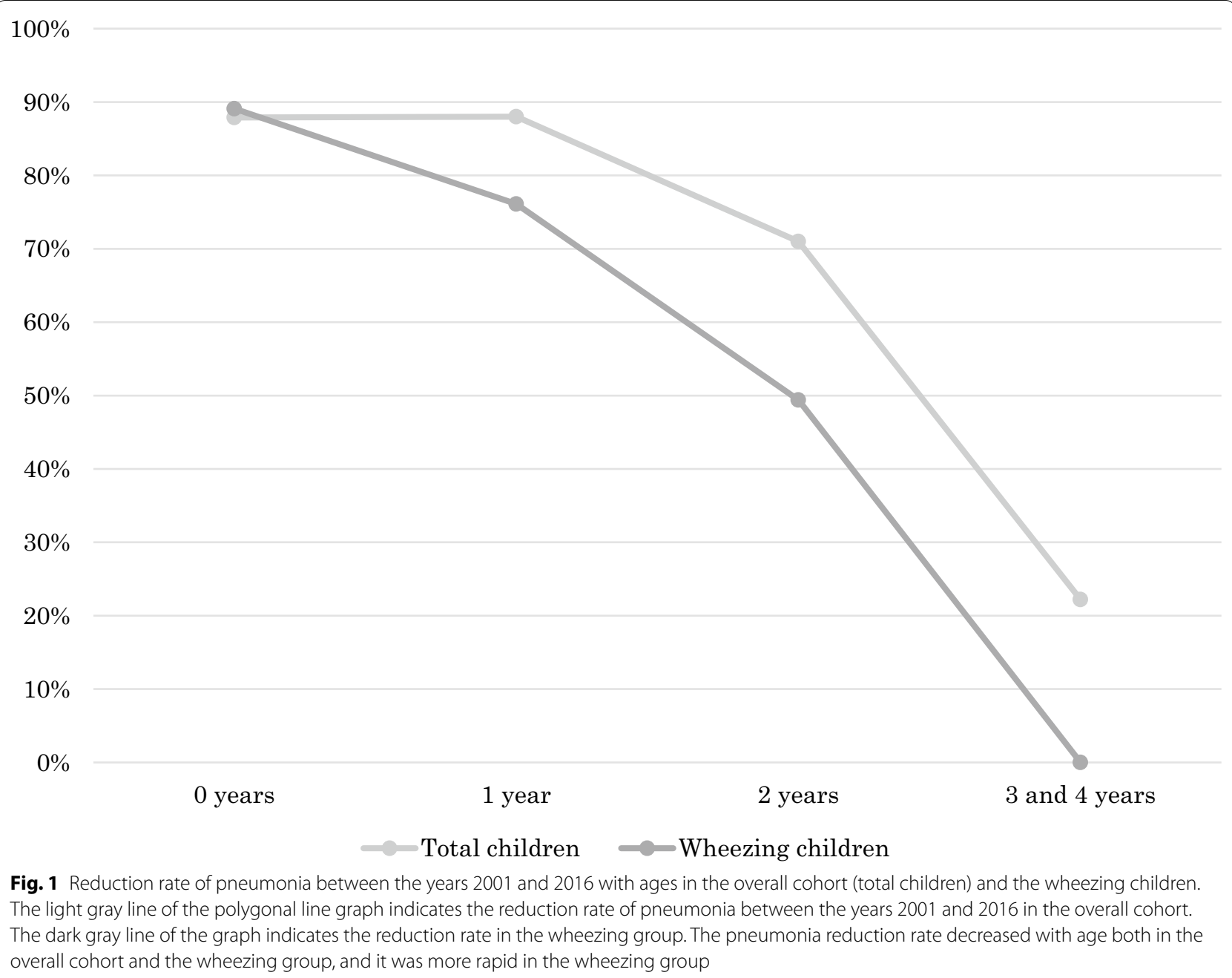


decreased from 2001 to 2016 in both the overall cohort and the wheezing group and the reduction rate in the history of pneumonia decreased as children grew older in both the overall cohort and the wheezing group, and it decreased more rapidly in the wheezing group (Fig. 1).

Whereas the participants of the 2001 study were most susceptible to pneumonia at the age of $<1$ year, the 2016 wheezing group were most susceptible to pneumonia at the age of 2 years. Whereas the pneumonia reduction rate was around $90 \%$ aged $<1$ year in both the overall cohort and the wheezing group, it decreased as the children grew older in both the overall cohort and the wheezing group and declined to less than $50 \%$ at the age 2 years (Fig. 1). The reduction in pneumonia development may be due to various measures which progressed during this time including Hib combination vaccination. Since other measures than Hib combination vaccination do not seem to have regressed during this period, the decline in the reduction rate may be attributable to Hib combination vaccination, which was started in 2009 before the participants of the 2016 study were born.

The effects of the Hib combination vaccination attenuate after 1 year or so when a booster dose is not administered [28]. The EPI of Bangladesh does not include a booster dose of the Hib combination vaccine, which likely resulted in the resurgence of pneumonia after 1 year of age (Tables 1 and 3). Table 2 shows the crude and adjusted ORs of the risk factors for wheezing. Pneumonia at the age of 1, 2 and 3-4 years was a risk factor for wheezing, whereas pneumonia at the age of $<1$ year was not. We previously found that pneumonia history at the ages of 0,1 , and 2 years was a risk factor for wheezing $[14,27]$. However, the present study did not show that a history of pneumonia at the age of $<1$ year was a significant risk factor. This might be due to the prevention of pneumonia at the age of $<1$ year by the Hib combination vaccination, whose efficiency then attenuated. These results are compatible with the fact that a booster dose of the Hib combination vaccine is not administered under the EPI in Bangladesh.

However, the reduction may be due to other measures, such as antibiotic use by the CHRWs, Vitamin A distribution, improved hospital care, improved referral, improved nutritional status, in the children aged $<1$ year. In the Matlab HDSS service area, where our studies were conducted, the number of deaths from respiratory diseases including pneumonia of children aged $<1$ year significantly decreased from 2001 to 2006 but no significant decrease was observed from 2008 to 2011, before and after the implementation of the Hib combination vaccination. Namely, Hib combination vaccination itself did not directly decrease the mortality from acute lower respiratory infections including pneumonia.

Among the measures taken, the effect on the reduction might have been attributable to Vitamin A distribution and improved nutritional status, since antibiotic use by CHRWs, improved hospital care and improved referral are related to the management of pneumonia and were unlikely to prevent pneumonia development. Figure 1 shows that the reduction rate of the development of pneumonia in the wheezing group declined faster than the overall cohort. It is unlikely that Vitamin A or nutritional improvements worked less effectively in the wheezing group, since they were not the risk factors for wheezing. Thus, the decline in the reduction rate in the wheezing group were more likely to be attributable to $\mathrm{Hib}$ combination vaccination rather than the other measures.

Three doses of Hib combination vaccine coverage in the Matlab HDSS service area has been more than $97 \%$ since the start of the vaccination [18-22] including the 2016 study participants (Table 1). DTP vaccination was widely in operation before introducing of the Hib combination vaccination with the three doses coverage more than $97 \%[23,24]$ including the 2001 study participants (data not shown). Since hepatitis B does not seem to affect wheezing, these imply that the reduction in pneumonia history could be attributable to Hib vaccination.

Bronchial asthma in childhood is usually divided into three groups. One is called transient early wheezers who develop lower respiratory tract infections during young infancy but recover in later childhood. The second is atopic type with high IgE levels and the third is intermediate onset wheezers. Since children who experienced pneumonia have a higher risk of developing asthma in subsequent years, the symptoms of wheezing in the present study were compatible with these transient early wheezeres. The role of anti-Ascaris IgE antibody for the wheezy children is still necessary to be clarified [29].

Other risk factors for wheezing were antibiotic use during infancy, and maternal and paternal asthma. Antibiotic use during the 1st year of life has been reported to increase the rate of asthma, probably because it affects the normal development of the intestinal microbiome, especially among early wheezers, who develop wheezing after recurrent respiratory infections but grow out eventually [30-32]. The findings of this study are consistent with the above report. Parental asthma is an established predisposing factor for asthma, and the results of this study confirmed this.

The strength of this study lies in the method used for the selection of the study population. The participants were randomly selected from the general population of an area where strict registration of vital events has long been done, even though the study was conducted in a 
low- to middle-income country. Another strength of this study is the high response rate of $92.1 \%$.

This study has certain limitations. First, different sampling methods were used. The 2001 study used random cluster sampling, while the 2016 study used random sampling [10]. Although the selection method differed, this guaranteed there was no selection bias in the two study populations. Second, the diagnostic criteria for pneumonia differed between the two studies [10]. Pneumonia was diagnosed based on the observed respiratory rate of the children by the guardians in the 2001 study, and this is regarded as the best method to detect pneumonia in a low-income country with limited resources. In the 2016 study, pneumonia was diagnosed by physicians according to the WHO guidelines, which were published after 2005 [21]. However, there was no significant difference in death rate between the years 2004 and 2007 (Fisher exact test; $p=0.584$ ) [33, 34], which is before and after the introduction of the WHO guidelines respectively, indicating that the difference in the diagnostic criteria mattered little on mortality (data not shown). Third, in the 2001 study, the sample-size calculation was based on the prevalence of pneumonia among the population [10], while in the 2016 study, it was based on the difference in the serum IgE levels. Fourth, we used paired t-test to compare the difference in pneumonia development with age to assess the impact of Hib combination vaccine between 2001 and 2016. The ' $n$ ' should be at least 30 for a valid a paired t-test. However, the ' $n$ ' is essentially 4 (at 0,1 , 2 and 3-4 years) in the comparison. This indicates the weakness of this analysis.

\section{Conclusions}

Hib combination vaccination shows a protective role against wheezing beyond target disease-specific protection at the age of $<1$ year among 5 -year-old children in rural Bangladesh, secondly due to the reduction of pneumonia. However, as a booster dose was not administered, this non-specific beneficial effect of this vaccination might have attenuated when the participants reached 1-4 years of age. An additional booster dose of Hib combination vaccine might further decrease the prevalence of childhood wheezing.

\footnotetext{
Abbreviations

Cl: Confidence interval; CHRW: Community health research workers; DTP Diphtheria, tetanus, and pertussis; EPI: Expanded Programme on Immunization; HDSS: Health and demographic surveillance system; Hib: Haemophilus influenzae Type b; icddr,b: International Centre for Diarrhoeal Disease Research, Bangladesh [formerly known as ICDDR,B]; OR: Odds ratio; RKS: Record Keeping System; SES: Socio-economic status; WHO: World Health Organization.
}

\section{Acknowledgements}

The authors thank the children who participated in our studies and their guardians. We thank the field research staff for their rigorous data collection. We also thank Prof. Shinji Nakahara for support with statistical analysis.

\section{Authors' contributions}

$H T, T I$, and AK made substantial contributions to the conception of this study. All authors contributed to the study design and protocol writing. SMTH, KZ, SKH, SY, SMA, JA, and AK contributed to data acquisition. HT, SMTH, KZ, $\mathrm{ST}, \mathrm{TI}$, and AK contributed to data analysis and interpretation. All authors were involved in drafting and revising the manuscript. All authors read and approved the final manuscript.

\section{Funding}

This work was funded by a Grant-in-Aid for Scientific Research (Basic Research (A), 26257507) in 2014-2016 from the Ministry of Education, Culture, Sports, Science and Technology, Japan. icddr,b thanks the governments of Bangladesh, Canada, Sweden, and the UK for their support.

\section{Availability of data and materials}

Some of the datasets analyzed in the current study are available in the following Scientific Reports of the health and demographic surveillance system; Demographic Surveillance System-Matlab, v. 22. Registration of demographic events 1991, Scientific Report No. 74. Dhaka: ICDDR,B.,

Demographic Surveillance System-Matlab, v. 28. Registration of demographic events 1996, Scientific Report No. 82. Dhaka: ICDDR,B.,

Health and Demographic Surveillance System-Matlab, v. 34. Registration of health and demographic events 2001, Scientific Report No. 90. Dhaka: ICDDR,B.,

Health and Demographic Surveillance System-Matlab, v. 40. Registration of health and demographic events 2006, Scientific Report No. 103. Dhaka: icddr,b.,

Health and Demographic Surveillance System-Matlab, v. 42. Registration of health and demographic events 2008, Scientific Report No. 109. Dhaka: icddr,b.,

Health and Demographic Surveillance System-Matlab, v. 45. Registration of health and demographic events 2011, Scientific Report No. 121. Dhaka: icddr,b.,

Health and Demographic Surveillance System-Matlab, v. 51. Registration of health and demographic events 2016, Scientific Report No. 138. Dhaka: icddr,b.,

Demographic Surveillance System-Matlab, v. 37. Registration of demographic events 2004, Scientific Report No. 93. Dhaka: ICDDR,B. Available from: http:// dspace.icddrb.org/jspui/handle/123456789/6494.

Demographic Surveillance System-Matlab, v. 41. Registration of demographic events 2007, Scientific Report No. 106. Dhaka: ICDDR,B. Available from: http:// dspace.icddrb.org/jspui/handle/123456789/6517.

They are available

from: http://dspace.icddrb.org/jspui/handle/123456789/6476 from: http://dspace.icddrb.org/jspui/handle/123456789/6514 from: http://dspace.icddrb.org/jspui/handle/123456789/6495 from: http://dspace.icddrb.org/jspui/bitstream/123456789/6500 from: http://dspace.icddrb.org/jspui/bitstream/123456789/6518 from: http://dspace.icddrb.org/jspui/handle/123456789/6521 from: http://dspace.icddrb.org/jspui/handle/123456789/9061 from: http://dspace.icddrb.org/jspui/handle/123456789/6494 from: http://dspace.icddrb.org/jspui/handle/123456789/6517

The other datasets generated and analyzed in the current study are not publicly available due to the restriction of the data only to the co-investigators of the study but are available from the corresponding author on reasonable request.

\section{Ethics approval and consent to participate}

The study protocol was approved by the Ethical Review Committee of icddr,b (PR-15054). The Ethics Committee of Tokyo Kasei University (Sayama H27-09), and The University of Tokyo (11018 and 2020180NI) approved the study. The protocol of our 2001 study was approved by the Ethical Review Committee of the International Centre for Diarrhoeal Disease Research, Bangladesh (2000038). As the studies involved human subjects, the ethical principles of the Declaration of Helsinki were followed. Written informed consent was obtained from the legal guardians of all participants. 


\section{Consent for publication}

Not applicable.

\section{Competing interests}

The authors declare that they have no competing interests.

\begin{abstract}
Author details
${ }^{1}$ Department of Community and Global Health, Graduate School of Medicine, The University of Tokyo, 7-3-1 Hongo, Bunkyo City, Tokyo 113-0033, Japan. ${ }^{2}$ Nutrition and Clinical Services Division, International Centre for Diarrhoeal Disease Research, Bangladesh (icddr,b), 68, Shaheed Tajuddin Ahmed Sarani, Mohakhali, Dhaka 1212, Bangladesh. ${ }^{3}$ Infectious Diseases Division, icddr,b, 68, Shaheed Tajuddin Ahmed Sarani, Mohakhali, Dhaka 1212, Bangladesh. ${ }^{4}$ Department of Developmental Medical Sciences, Graduate School of Medicine, The University of Tokyo, 7-3-1 Hongo, Bunkyo City, Tokyo 113-0033, Japan. ${ }^{5}$ Infectious Disease Surveillance Center, National Institute of Infectious Diseases, 1-23-1 Toyama, Shinjuku City, Tokyo 162-8640, Japan. ${ }^{6}$ Organization for Population Health Environment \& Nutrition, Adilpur Shastitala, Taltala Kheyaghat Road, Abhaynagar, Jashore 7460, Bangladesh. ${ }^{7}$ Department of Biochemistry and Microbiology, North South University, Bashundhara, Dhaka 1212, Bangladesh. ${ }^{8}$ Department of Microbiology, Biomedicine Discovery Institute, Monash University, Clayton, VIC 3800, Australia. ${ }^{9}$ The Graduate School of Humanities and Life Sciences, Tokyo Kasei University, 1-18-1 Kaga, Itabashi City, Tokyo 173-8602, Japan.
\end{abstract}

Received: 24 September 2020 Accepted: 19 January 2021 Published online: 03 February 2021

\section{References}

1. Bousquet J, Jeffery PK, Busse WW, Johnson M, Vignola AM. Asthma from bronchoconstriction to airways inflammation and remodeling. Am J Respir Crit Care Med. 2000;161:1720-45. https://doi.org/10.1164/ajrcc m.161.5.9903102.

2. Burrows B, Martinez FD, Halonen M, Barbee RA, Cline MG. Association of asthma with serum IgE levels and skin-test reactivity to allergens. N Engl J Med. 1989;320:271-7. https://doi.org/10.1056/NEJM198902023200502.

3. Sears MR, Burrows B, Flannery EM, Herbison GP, Hewitt CJ, Holdaway MD. Relation between airway responsiveness and serum lgE in children with asthma and in apparently normal children. N Engl J Med. 1991;325:106771. https://doi.org/10.1056/NEJM199110103251504.

4. Evans R III, Mullally DI, Wilson RW, Gergen PJ, Rosenberg HM, Grauman JS, et al. National trends in the morbidity and mortality of asthma in the US. Prevalence, hospitalization and death from asthma over two decades: 1965-1984. Chest. 1987;91S:65S-74S.

5. Gergen PJ, Mullally DI, Evans R 3rd. National survey of prevalence of asthma among children in the United States, 1976 to 1980. Pediatrics. 1988;81:1-7.

6. Weitzman M, Gortmaker SL, Sobol AM, Perrin JM. Recent trends in the prevalence and severity of childhood asthma. JAMA. 1992;268:2673-7.

7. The International Study of Asthma and Allergies in Childhood (ISAAC) Steering Committee. Worldwide variation in prevalence of symptoms of asthma, allergic rhinoconjunctivitis, and atopic eczema: ISAAC. Lancet. 1998;351:1225-32.

8. Pearce N, Ait-Khaled N, Beasley R, Mallol J, Keil U, Mitchell E, et al. Worldwide trends in the prevalence of asthma symptoms: phase III of the International Study of Asthma and Allergies in Childhood (ISAAC). Thorax. 2007;62:758-66. https://doi.org/10.1136/thx.2006.070169.

9. Zaman K, Takeuchi H, Md Yunus, Arifeen SEL, Chowdhury HR, Baqui AH, et al. Asthma in rural Bangladeshi children. Ind J Pediatr. 2007;74:539-43. https://doi.org/10.1007/s12098-007-0104-0.

10. Takeuchi H, Khan MA, Ahmad SM, Hasan SMT, Md Alam J, Takanashi S, et al. Concurrent decreases in the prevalence of wheezing and Ascaris infection among 5-year-old children in rural Bangladesh and their regulatory $T$ cell immunity after the implementation of a national deworming program. Immun Inflamm Dis. 2019;7:160-9. https://doi.org/10.1002/ iid3.253.

11. Hassan MR, Kabir AR, Mahmud AM, Rahman F, Hossain MA, Bennoor $\mathrm{KS}$, et al. Self-reported asthma symptoms in children and adults of
Bangladesh: findings of the National Asthma Prevalence Study. Int J Epidemiol. 2002;31:483-8.

12. Kabir ML, Rahman F, Hassan MQ, Ahamed F, Mridha MA. Asthma, atopic eczema and allergic rhino-conjunctivitis in school children. Mymensingh Med J. 2005;14:41-5.

13. Hawlader MD, Ma E, Noguchi E, Itoh M, Arifeen SE, Perssonet LÅ, et al. Ascaris lumbricoids infection as a risk factor for asthma and atopy in rural Bangladeshi children. Trop Med Health. 2014;42:77-85. https://doi. org/10.2149/tmh.2013-19.

14. Takeuchi H, Khan MA, Zaman K, Takanashi S, Hasan SMT, Yunus MD, et al. Classification of wheezing children in rural Bangladesh by intensity of Ascaris infection, total and specific lgE levels, history of pneumonia, and other risk factors. J Immunol Res. 2019;2019:4236825. https://doi. org/10.1155/2019/4236825.

15. Baqui AH, Sabir AA, Begum N, Arifeen SE, Mitra SN, Black RE. Causes of childhood deaths in Bangladesh: an update. Acta Paediatr. 2001;90:682-90.

16. Baqui AH, El Arifeen S, Saha SK, Persson L, Zaman K, Gessner BD, et al. Effectiveness of Haemophilus influenzae type $B$ conjugate vaccine on prevention of pneumonia and meningitis in Bangladeshi children: a case-control study. Pediatr Infect Dis J. 2007;26:565-71. https://doi. org/10.1097/INF.0b013e31806166a0.

17. Chen WJ, Moulton LH, Saha SK, Mahmud AA, Arifeen SE, Baqui AH. Estimation of the herd protection of Haemophilus influenzae type b conjugate vaccine against radiologically confirmed pneumonia in children under 2 years old in Dhaka, Bangladesh. Vaccine. 2014;32:944-8. https:// doi.org/10.1016/j.vaccine.2013.12.052.

18. Demographic Surveillance System-Matlab, v. 22. Registration of demographic events 1991, Scientific Report No. 74. Dhaka: ICDDR,B. http:// dspace.icddrb.org/jspui/handle/123456789/6476. Accessed 22 Sept 2020.

19. Demographic Surveillance System-Matlab, v. 28. Registration of demographic events 1996, Scientific Report No. 82. Dhaka: ICDDR,B. http:// dspace.icddrb.org/jspui/handle/123456789/6514. Accessed 22 Sept 2020.

20. Health and Demographic Surveillance System-Matlab, v. 34. Registration of health and demographic events 2001, Scientific Report No. 90. Dhaka: ICDDR,B. http://dspace.icddrb.org/jspui/handle/123456789/6495. Accessed 22 Sept 2020.

21. Health and Demographic Surveillance System-Matlab, v. 40. Registration of health and demographic events 2006, Scientific Report No. 103. Dhaka: icddr,b. http://dspace.icddrb.org/jspui/bitstream/123456789/6500. Accessed 22 Sept 2020.

22. Health and Demographic Surveillance System-Matlab, v. 42. Registration of health and demographic events 2008, Scientific Report No. 109. Dhaka: icddr,b. http://dspace.icddrb.org/jspui/bitstream/123456789/6518. Accessed 22 Sept 2020.

23. Health and Demographic Surveillance System-Matlab, v. 45. Registration of health and demographic events 2011, Scientific Report No. 121. Dhaka: icddr,b. http://dspace.icddrb.org/jspui/handle/123456789/6521. Accessed 22 Sept 2020

24. Health and Demographic Surveillance System-Matlab, v. 51. Registration of health and demographic events 2016, Scientific Report No. 138. Dhaka: icddr,b. http://dspace.icddrb.org/jspui/handle/123456789/9061. Accessed 22 Sept 2020

25. Asher MI, Keil U, Anderson HR, Beasley R, Crane J, Martinez F, et al. International Study of Asthma and Allergies in Childhood (ISAAC): rationale and methods. Eur Respir J. 1995;8:483-91.

26. World Health Organization. Pocket book of hospital care for children: guidelines for the management of common illnesses with limited resources. Geneva: World Health Organization; 2005.

27. Takeuchi H, Zaman K, Takahashi J, Yunus M, Chowdhury HR, Arifeen SEL, et al. High titre of anti-Ascaris immunoglobulin E associated with bronchial asthma symptoms in 5-year-old rural Bangladeshi children. Clin Exp Allergy. 2008;38:276-82. https://doi.org/10.1111/j.1365-2222.2007.02890 .x.

28. Ladhani SN. Two decades of experience with the Haemophilus influenzae serotype b conjugate vaccine in the United Kingdom. Clin Ther. 2012;34:385-99. https://doi.org/10.1016/j.clinthera.2011.11.027.

29. Takeuchi H, Khan AF, Yunus M, Hasan MI, Hawlader MDH, Takanashi $\mathrm{S}$, et al. Anti-Ascaris immunoglobulin E associated with bronchial 
hyper-reactivity in 9-year-old rural Bangladeshi children. Allergol Int. 2016;65(2):141-6. https://doi.org/10.1016/j.alit.2015.07.002.

30. Rusconi F, Gagliardi L, Galassi C, Forastiere F, Brunetti L, La Grutta S, SIDRIA-2 Collaborative Group, et al. Paracetamol and antibiotics in childhood and subsequent development of wheezing/asthma: association or causation? Int J Epidemiol. 2011;40:662-7. https://doi.org/10.1093/ije/ dyq263.

31. Alm B, Erdes L, Möllborg P, Pettersson R, Norvenius SG, Aberg N, et al. Neonatal antibiotic treatment is a risk factor for early wheezing. Pediatrics. 2008;121:697-702. https://doi.org/10.1542/peds.2007-1232.

32. Ong MS, Umetsu DT, Mandl KD. Consequences of antibiotics and infections in infancy: bugs, drugs, and wheezing. Ann Allergy Asthma Immunol. 2014;112(441-445):e1. https://doi.org/10.1016/j.anai.2014.01.022.
33. Demographic Surveillance System-Matlab, v. 37. Registration of demographic events 2004, Scientific Report No. 93. Dhaka: ICDDR,B. http:// dspace.icddrb.org/jspui/handle/123456789/6494. Accessed 22 Sept 2020.

34. Demographic Surveillance System-Matlab, v. 41. Registration of demographic events 2007, Scientific Report No. 106. Dhaka: ICDDR,B. http:// dspace.icddrb.org/jspui/handle/123456789/6517. Accessed 22 Sept 2020.

\section{Publisher's Note}

Springer Nature remains neutral with regard to jurisdictional claims in published maps and institutional affiliations.
Ready to submit your research? Choose BMC and benefit from:

- fast, convenient online submission

- thorough peer review by experienced researchers in your field

- rapid publication on acceptance

- support for research data, including large and complex data types

- gold Open Access which fosters wider collaboration and increased citations

- maximum visibility for your research: over $100 \mathrm{M}$ website views per year

At BMC, research is always in progress.

Learn more biomedcentral.com/submissions 